\title{
Effect of natural apophyseal glides on cervicogenic headache: A randomized controlled trial
}

\author{
Ghada Ismail Mohamed ${ }^{1 *}$, Wael Salah Shendy ${ }^{2}$
}

*Correspondence: drdodfy2007@outlook.com

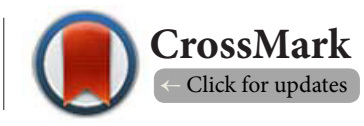

'Basic Science Department, Faculty of Physical Therapy, Cairo University, Giza, Egypt.

2Physical Therapy for Neuromuscular disorders and its surgery Department, Faculty of Physical Therapy, Cairo University, Giza, Egypt.

\begin{abstract}
Background: Headache is that the most prevailing pain disorder, affecting sixty six percent of the worldwide population. Cervicogenic headache may be a common condition inflicting significant disability.

Purpose: To determine the efficacy of Mulligan Natural apophyseal glides (NAGs) on pain intensity level, functional ability and cervical range of motion in subjects with cervicogenic headache.

Methods: Thirty patients with clinicaldiagnosis of cervicogenic headache were assigned randomly into two groups: Group (A) patients received conventional physical therapy program 3 sessions per week for 4 weeks. Group (B) patients received conventional physical therapy program in addition to Mulligan, natural apophyseal glides (NAGs) 3 sessions per week for 4 weeks. Pain intensity level, neck functional disability level, and cervical range of motion were measured pre and post intervention period.

Results: Patients of bothgroups showed statistical significant improvement in all the measured variables after treatment program. Between groups difference the natural apophyseal glides group (B) showed a statistical significant improvement in pain intensity level, neck functional disability level than in group (A) but there was no statistical significant difference between both groups in cervical range of motion ( $\mathrm{p}$ value $<0.05)$.
\end{abstract}

Conclusions: Mulligan (natural apophyseal glides) had an effect on decreasing pain intensity level, improving functional abilityand cervical range of motion in patients with cervicogenic headache.

Keywords: Cervicogenic Headache, Natural Apophyseal Glides

\section{Introduction}

Physiotherapists commonly come across patients complaining of headache in their clinical practice [1]. Headache can be classified as primary or secondary. Primary headache originates from a vascular or muscular source such as tension-type headache. Secondary headache is related to other structures with cervicogenic headache (CGH) being the most common type that is related to cervical spine dysfunction $[2,3]$.

The International Headache Society (IHS) defined cervicogenic headache as "pain caused by neck source and perceived in one or more parts of the head and/or face" [4]. It accounts for 15\% to $20 \%$ of cases of chronic and recurrent headache $[4,5]$. CGH may originate from different structures of the cervical spine including the zygapophyseal joints (occiput-C3) [6,7]. This type of headache has been found to be four times more common in subjects with musculoskeletal symptoms [8]. Also, individuals with neck pain are more frequently exposed to headache than those with symptoms in other areas [9].

Subjects with chronic cervicogenic headache have considerable limitation of daily function, restriction of social participation, and emotional distress with profound impact on quality of life $[10,11]$. Major signs and symptoms of CGH include unilateral head pain without side-shift, with neck pain and limitation of neck movement [12]. Muscle dysfunction is an important feature of $\mathrm{CGH}$. Various studies have shown significant hypomobility of craniocervical joints and impaired overall mobility of 
cervical spine $[5,6]$. Moreover, muscle tightness especially of the upper trapezius and sternocleidomastoid muscles with impaired strength and neuromotor contract of the cervical flexors(superficial and deep) are frequently encountered in subjects with CGH [13].

However, diagnosis of cervicogenic headache is difficult because up to $70 \%$ of subjects with frequent intermittent headache report accompanying neck pain [14]. It is therefore logical that subjects who experience headaches may receive unwarranted treatment to the neck unless an accurate, exact assessment is made [15].

Different therapeutic approaches have been proposed for treatment of headaches; with physical therapy, pharmacological drugs, and cognitive therapies the most commonly used [9] . Several studies reported that manual therapy of the cervical spine can decrease pain intensity, frequency, and duration in addition to reducing in neck pain and disability [16]. Jull et al. [17] reported that neck exercises are effective in the management of cervicogenic headache.

Mulligan Natural apophyseal glides (NAGs) are oscillatory mobilizations which can be applied to the facet joints and graded according to the tolerance of the patient. They are used to increase spinal movement and decrease the pain associated with it [18]. Mulligan Techniques have mechanical and neurological effects, resulting in a sympatheoexcitatory effect which may be instrumental in producing an analgesic response[19]. NAGs mobilization technique produces a fast and long-term effect in pain reduction and improvement of range of motion with functional activities in subjects with pain and stiffness of the neck [20]. Although the Mulligan technique is frequently used in clinical practice, there is limited evidence about its effect, in the treatment of CGH.

Therefore, the purpose of this study was to determine the efficacy of natural apophyseal glides (NAGs) on pain intensity, functionalabilityand cervical range of motion in subjects with cervicogenic headache.

\section{Material and methods \\ Design of the study \\ Pretest-Posttest randomized controlled experimental design was used in this study.}

\section{Subjects}

Thirty patients ( 10 males and 20 females) with cervicogenic headache were selected from the outpatient clinic of the faculty of physical therapy, Cairo University. They assigned randomly using a random sequence generator to one of the two study groups. Subjects were recruited using publically distributed posters, online social media, and by verbal invitation. Subjects participated in the current study after approval of ethical committee of faculty of physical therapy, Cairo University with number (P.T.REC /012/001815) and all subjects provided written informed consent.

Subjects whose age ranged from 20 to 40 and BMI ranged from $18.5-24.9 \mathrm{~kg} / \mathrm{m}^{2}$. were selected. The study procedureswere explained. Group(A) control group included 15 CGH patients, with a mean age of (26.64 \pm 2.23 ) years ( 6 male and 9 female), received the conventional physical therapy program (hot packs, isometric neck flexor strengthening exercises, chin in exercises for deep neck flexor muscles and stretching exercise for upper trapezius and sternocleidomastoid muscles) 3 session per week for 4 weeks. Group(B) experimental group included $15 \mathrm{CGH}$ patients, with a mean age of $(25.86 \pm 3.62)$ years ( 4 male and 11 female) received Mulligan NAGs technique in addition to the conventional physical therapy program 3 session per week for 4 weeks.

\section{Inclusion criteria}

All participants were referred from physicians. They were diagnosed with CGH matching CGH diagnostic criteria established by international headache society, had unilateral headache without side shift, headache with neck stiffness and or pain, headache frequency of at least once per week over a period of 3 months.

\section{Exclusive criteria}

If they had headache not of cervical origin, headache with any associated symptoms like dizziness or visual disturbance, history of any surgeryaround cervical region, sever trauma, disc prolapse, spinal stenosis, specified bilateral headache, pregnancy, as well as frequent migraine.

\section{Sample-size determination}

For sample size estimation of the study, $80 \%$ power, 0.05 type one error ( 2 tailed) and effect size of $0.90 ; 15$ subjects were recruited in each group and total number recruited was 30. G*power 3.1 software (Universities, Dusseldorf, Germany) was used for calculation.

\section{Instrumentation \\ 1)Numerical Pain Rating Scale (NPRS)}

The NPRS is a valid and reliable scale to measure pain intensity [21]. (NPRS; 0-10) is utilized to assess pain intensity level, where 0 indicates no pain and 10 indicates maximum pain. Measurement results of NPRS for all participants showed average pain rating [22].

\section{2)Neck disability index (NDI)}

Neck Disability Index (NDI) is considered a reliable and valid measurement for the disability accompanying neck pain. The Arabic version of NDI was used in the current study to investigate pain intensity level in Arabic speaking patients suffering from CGH [14]. The Arabic version of NDI has two factors with ten items structure and has proven to be a reliable, valid, and responsive tool [23].

\section{3) Myrin goniometer $(\mathrm{OB})$}

Myrin goniometer was utilized to measure cervical range of 
motion (ROM). This measurement tool consists of a compass needle affected by the earth's magnetic field and an inclination needle affected by gravity. The compass needle measures motion on the horizontal plane, and the inclination needle measures motion on the vertical plane. Thus, it has proven to be reliable and valid for neck ROM measurement [24].

All measures were assessed by an assessor blinded to group allocation before intervention and reassessed in similar way following 4-weeks intervention had been completed.

\section{Procedures}

The current study consisted of three Stages: Pre-test measurements, Intervention period and Post-test measurements:

\section{Pre-test measurements}

\section{Pain intensity level measurement}

The patient was asked to place mark at his/her level of pain at sheet of NPRS.

\section{Neck functional disability level measurement}

The neck functional disability level was measured by the neck disability index (NDI) pre and post treatment. In this study we used the Arabic version of the NDI.

\section{Cervical ROM measurement}

The cervical ROM by Myrin goniometer in all directions (flexion, extension, side bending and rotation) was measured. The patient was seated in erect and comfortable position while his/her feet were placed flat on the floor. Knee kept in right angle. The strap was fixed around the head with the instrument at the side. The inclination needle was set at zero. The head was bent forward (neck flexion), and backward (neck extension). The instrument was placed at the front or the back. The inclination needle was reset again at zero, the neck was bent to right side (right lateral flexion) and was bent to the left side (left lateral flexion), The patient sat on low stool with his/her head erect. The straps were fixed round the head and over the vertex. The compass needle was set at zero. The patient was asked to rotate his/ her neck to the right side (right rotation), and to the left side (left rotation). The mean of 3 repetitions was calculated for each type of movement and used for the analysis.

\section{Intervention}

\section{Group (A)}

Participants of this group received conventional physical therapy program three sessions per week for four weeks. This program included 4 components; 1 ) hot packs application prior to exercise. An electric hot pack for cervical region 10 $\mathrm{x} 16$ inches. It was done from sitting position for 20 minutes on cervical region with head resting on a pillow [13].

2)passive stretching for upper trapeziusby contra lateral side bending, the patient placed in sitting position and the head-neck region was passively bent on right side (to stretch left side) to the restrictive barrier and asked the patient not to move the shoulder [13], and passive stretching sternocleidomastoid the patient placed in sitting position, slowly brought patient's head from the neutral position into a position of contralateral side flexion, ipsilateral rotation, , and slight extension [25]. Stretching exercises 6-15 seconds for 3 times repetition.

3)Isometric neck flexion exerciseswere performed from sitting position, low back support was provided with hold for 6 seconds, and then relax for 6 seconds. These procedures were repeated 15 times (Figure 1).

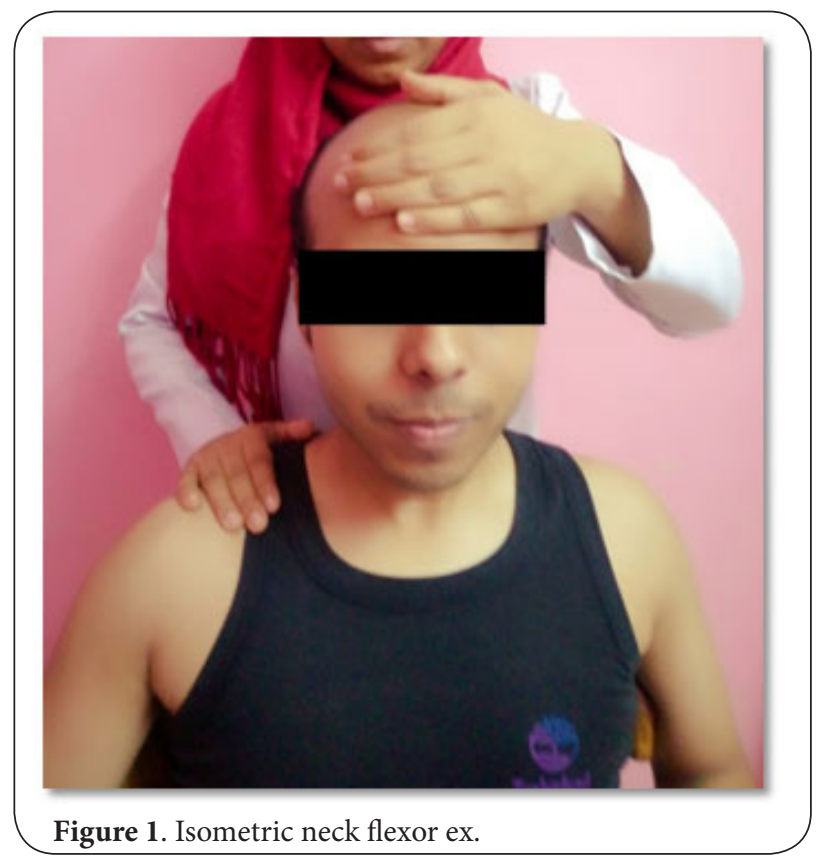

4) and chin in exercises (for deep neck flexor muscles)were performed from supine lying position, in these exercises, a roll of towel was placed which wasplaced suboccipitally to monitor the subtle flattening of the cervical lordosis that occurswith the contraction of the longus colli muscle. The patient asked to carefully nod his head as he was saying "yes" while not restoring to retraction, while not strictly involvement of superficial flexors, and without fast, jerky cervical flexion movement and hold for thirty seconds and recurrent 3 times [26].

\section{Group (B)}

Participants of this group received conventional physical therapy programin addition to NAGs technique. The patient was seated on low chair in erect and comfortable position. The therapist stood facing the patient in step stance posture stabilizing patient's shoulder/trunk. Painless oscillatory mid to end-range mobilization was applied in the plane of the facet joints (upward direction). It was applied between C4-C5 and $\mathrm{C} 5-\mathrm{C} 6$.

The therapist's middle phalanx of left little finger was 
placed under the Spinous process of the superior vertebra of the mobilized segment. The other fingers on that hand were wrapped around the occiput, stabilizing the head. The lateral border of the thenar eminence of right hand partially covered the little finger of the therapist left hand. The therapist took up slack in the soft tissue to come into contact with the vertebrae to be moved. It was applied with 2 hertz in 3 sets, whereas glides were rhythmical. Mobilizations were repeated 6 times. The program was performed for three sessions per week for four weeks (Figure 2).

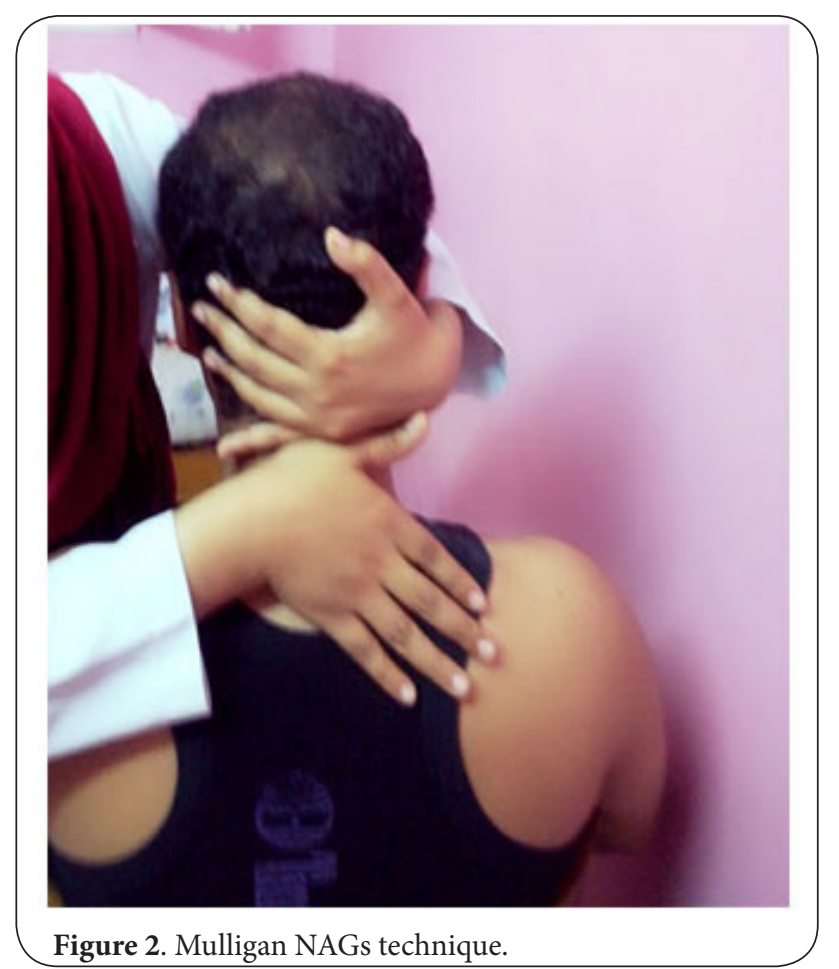

Both groups were treated under the same conditions and each subject was treated individually to avoid influencing one another.

\section{Post-test measurements}

Pain intensity level, Neck functional disability level, and cervical ROM measurements were conducted twice pretest measurements and after the intervention period to determine its effect.

\section{Data analysis and statistical design}

All statistical analysis was carried out by using the SPSS computer program, version 20. Data were expressed as mean \pm standard deviation (SD). Descriptive data and t-test were used for comparison of the mean age, height, weight and body mass index (BMI). Mean changes within groups (pre and poststudy) were analyzed using Paired T-test while mean changes between groups (pre and post-study) were analyzed using unpaired T-test to test hypothesis between groups. The level of significance was set at $p<0.05$.

\section{Results}

This study was conducted todetermine the efficacy of natural apophyseal glides (NAGs) on pain intensity, functional ability and cervical range of motion in subjects with cervicogenic headache. Thirty subjects were assigned randomly into two equal groups.

\section{Group (A)}

Fifteen CGH patients received conventional physical therapy program. The data in (Table 1) represented their mean age $(26.64 \pm 2.23)$ years, weight $(66.9 \pm 8.3) \mathrm{kg}$, height $(165.8 \pm 5.23)$ $\mathrm{cm}$ and BMI $(24.8 \pm 2.18) \mathrm{kg} / \mathrm{m} 2$.

\section{Group (B)}

Fifteen CGH patients $r$ received conventional physical therapy in addition to NAGstechnique The data in (Table 1) represented their mean age $(25.86 \pm 3.62)$ years, weight $(67 \pm 6.22)$ $\mathrm{kg}$, height $(163.8 \pm 4.5) \mathrm{cm}$ and BMI $(24.3 \pm 1.96) \mathrm{kg} / \mathrm{m} 2$. There was no significant difference between two groups in their mean age, weight, height and BMI.

Table 1. General Characteristics of the Subjects in both groups.

\begin{tabular}{lllll}
\hline Items & Age (Year) & $\begin{array}{l}\text { Weight } \\
(\mathbf{k g})\end{array}$ & $\begin{array}{l}\text { Height } \\
(\mathbf{c m})\end{array}$ & $\begin{array}{l}\text { BMI } \\
\left(\mathbf{k g} / \mathbf{m}^{2}\right)\end{array}$ \\
\hline Group A mean \pm SD & $26.64 \pm 2.23$ & $66.9 \pm 8.3$ & $165.8 \pm 5.23$ & $24.8 \pm 2.18$ \\
Group B mean \pm SD & $25.86 \pm 3.62$ & $67 \pm 6.22$ & $163.8 \pm 4.5$ & $24.3 \pm 1.96$ \\
t-value & 0.546 & -0.025 & 1.121 & 0.605 \\
P-value & 0.589 & 0.980 & 0.272 & 0.550 \\
P $<0.05$ & $\mathrm{NS}$ & $\mathrm{NS}$ & $\mathrm{NS}$ & $\mathrm{NS}$ \\
\hline
\end{tabular}

Pre study means values within both groups As shown in Table 2, There were no significant differences between two groups pre-study in pain intensity level, NDI and neck ROM where P-values were greater than 0.05 .

\section{Post study means values within both groups}

As shown in Table 3, There were no significant differences between two groups post-study in neck ROM where P-values were greater than 0.05 .

Comparison between pre and post study for group $\mathrm{A}$ As shown in Table 4, for group A, there were significant differences in pain intensity level, NDI and neck ROM between pre and post-study, where P-value were less than (0.05).

Comparison between pre and post study for group B As shown in Table 5, for group B, there were significant differences in pain intensity level, NDI and neck ROM between pre and post-study, where P-value were less than (0.05).

\section{Discussion}

In the twenty-first century, headachesare very common and 
Mohamed et al, Physical Therapy and Rehabilitation 2018,

Table 2. Pre-study mean values of measured variables for both groups.

\begin{tabular}{|c|c|c|c|c|c|}
\hline \multicolumn{2}{|c|}{ Pre-study } & $\begin{array}{l}\text { Group A } \\
\text { Mean } \pm \text { SD }\end{array}$ & $\begin{array}{l}\text { Group B } \\
\text { Mean } \pm \text { SD }\end{array}$ & t-value & P-value \\
\hline \multicolumn{2}{|c|}{ Pain intensity level } & $6.70 \pm 2.45$ & $5.80 \pm 1.75$ & -0.905 & 0.373 \\
\hline \multicolumn{2}{|c|}{ Neck disability index } & $14.6 \pm 5.57$ & $14.86 \pm 4.37$ & 0.146 & 0.885 \\
\hline \multirow{6}{*}{ 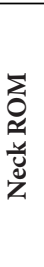 } & flexion LT & $35.33 \pm 4.76$ & $36.53 \pm 4.6$ & 0.7 & 0.490 \\
\hline & extension & $36.66 \pm 3.95$ & $37.06 \pm 3.86$ & 0.28 & 0.781 \\
\hline & Rt lateral flexion & $34.53 \pm 5.96$ & $37.73 \pm 4.19$ & 1.69 & 0.1 \\
\hline & Lt lateral flexion & $37.33 \pm 4.04$ & $35.46 \pm 7.8$ & 0.822 & 0.418 \\
\hline & Rt Rotation & $51.73 \pm 8.37$ & $51.13 \pm 7.18$ & 0.211 & 0.835 \\
\hline & Lt Rotation & $53.66 \pm 10.2$ & $49.26 \pm 9.7$ & 1.207 & 0.238 \\
\hline
\end{tabular}

Table 3. Post-study mean values of measured variables for both groups.

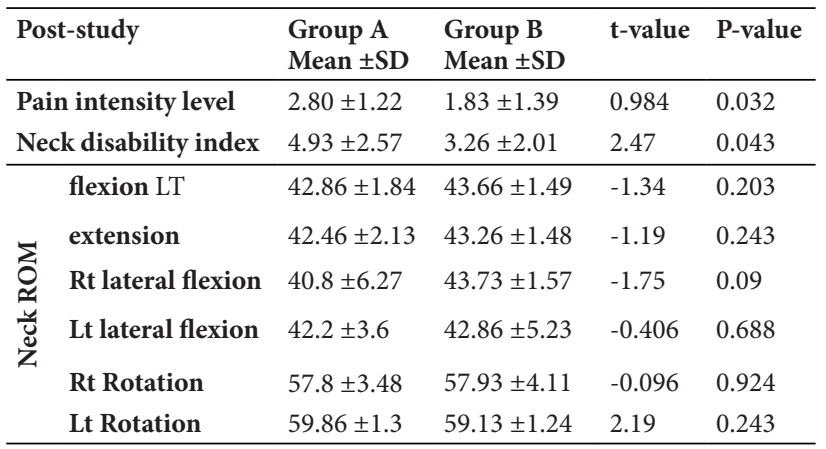

cause substantial pain and disability [27]. Cervicogenic headache is a secondary headache, which means "head pain with a cervical source". Prevalence rates for CGH within the general population varied from $0.4 \%$ to $2.5 \%$ and in some researches up to $4.1 \%$ [25]. Cervicogenic headache associated with ahigh burden of suffering and considerable socio-economic cost [27]. Although the Mulligan technique is frequently used in clinical practice, there is limited evidence about its effect, in the treatment of CGH. So, the purpose of this study was to investigate the efficacy of Mulligan (NAGs) on cervicogenic headache regarding reduction of pain intensity level, increasing cervical range of motion and improving in functional ability.

Our results revealed that there were significant differences in pain intensity level, NDI and neck ROM between pre and post-study for both groups. Also, the result revealed that there were statistical significant differences between both groups in favour to NAGs group post-study in pain intensity level, NDI. While there were no significant differences between two groups post-study in neck ROM.

The results indicated that NAGs group showed a significant decrease in pain intensity level and significant improvement in functional ability than the other group.

Mulligan techniques have both mechanical and neurological effects, Exelby L. [28], argued that the zygoapophyseal joints guide the spine and so improving their glide by applying NAGs and SNAGs will increase the range of spinal movement. Also, they may cause hypoalgesic effects by many mechanisms, a) Local mechanical disturbance which may modify the chemical environment, altering the concentration of inflammatory mediators. b) Movement may also trigger segmental inhibitory mechanisms. c) Activate the descending pain inhibitory systems, mediated supraspinally that involves serotonin and noradrenalin receptors in the spinal cord. d) Sympathetic nervous system and motor system excitation [29].

In the available literature, there is limited researches that studied the effect of NAGS on CGH. A few studies support the current findings.

Gautam R et al. [30] conducted a comparative study between Maitland and Mulligan Mobilization in improving neck pain range of motion (ROM) and disability. This study validated that Mulligan mobilization was more effective in reducing neck pain, disability and improving ROM. Kumar D [19], investigated the effectiveness of Mulligan NAGS in neck pain and stiffness. It was concluded that NAGs is a beneficial mobilization technique for providing faster and prolonged effect in reducing pain and improving range of motions with functional activities

The finding of this study come in agreement with Ali et al. [31] who investigated the efficiency of sustained natural apophyseal glides SNAGs with and without isometric exercise training in nonspecific neck pain. They found that when

Table 4. Pre-study post-study mean values of measured variables for group A.

\begin{tabular}{|c|c|c|c|c|c|c|}
\hline \multicolumn{2}{|c|}{ Group A } & $\begin{array}{l}\text { Pre-study } \\
\text { Mean } \pm \text { SD }\end{array}$ & $\begin{array}{l}\text { Post-study } \\
\text { Mean } \pm \text { SD }\end{array}$ & $\%$ of change & t-value & P-value \\
\hline \multicolumn{2}{|c|}{ Pain intensity level } & $6.70 \pm 2.45$ & $2.80 \pm 1.22$ & $58.2 \%$ & -10.2 & $0.000^{*}$ \\
\hline \multicolumn{2}{|c|}{ Neck disability index } & $14.6 \pm 5.57$ & $4.93 \pm 2.57$ & $66.23 \%$ & -7.4 & $0.000^{*}$ \\
\hline \multirow{6}{*}{$\begin{array}{l}\sum_{0} \\
\text { zu } \\
\text { ü } \\
\text { ż }\end{array}$} & flexion LT & $35.33 \pm 4.76$ & $42.86 \pm 1.84$ & $21.31 \%$ & 6.45 & $0.000^{*}$ \\
\hline & extension & $36.66 \pm 3.95$ & $42.46 \pm 2.13$ & $15.82 \%$ & 9.37 & $0.000^{*}$ \\
\hline & Rt lateral flexion & $34.53 \pm 5.96$ & $40.8 \pm 6.27$ & $18.15 \%$ & 4.21 & $0.001^{*}$ \\
\hline & Lt lateral flexion & $37.33 \pm 4.04$ & $42.2 \pm 3.6$ & $13 \%$ & 6.44 & $0.000^{*}$ \\
\hline & Rt Rotation & $51.73 \pm 8.37$ & $57.8 \pm 3.48$ & $11.73 \%$ & 3.07 & $0.008^{*}$ \\
\hline & Lt Rotation & $53.66 \pm 10.2$ & $59.86 \pm 1.3$ & $11.55 \%$ & 2.36 & $0.033^{*}$ \\
\hline
\end{tabular}


Mohamed et al, Physical Therapy and Rehabilitation 2018,

Table 5. Pre-study post-study mean values of measured variables for group B.

\begin{tabular}{|c|c|c|c|c|c|c|}
\hline \multicolumn{2}{|c|}{ Group B } & $\begin{array}{l}\text { Pre-study } \\
\text { Mean } \pm \text { SD }\end{array}$ & $\begin{array}{l}\text { Post-study } \\
\text { Mean } \pm \text { SD }\end{array}$ & $\%$ of change & t-value & P-value \\
\hline \multicolumn{2}{|c|}{ Pain intensity level } & $5.80 \pm 1.75$ & $1.83 \pm 1.39$ & $68.96 \%$ & -13.4 & $0.000^{*}$ \\
\hline \multicolumn{2}{|c|}{ Neck disability index } & $14.86 \pm 4.37$ & $3.26 \pm 2.01$ & $71.33 \%$ & -9.92 & $0.000^{*}$ \\
\hline \multirow{6}{*}{ 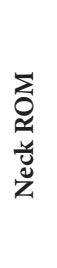 } & flexion $\mathrm{LT}$ & $36.53 \pm 4.6$ & $43.66 \pm 1.49$ & $19.5 \%$ & 5.07 & $0.000^{*}$ \\
\hline & Extension & $37.06 \pm 3.86$ & $43.26 \pm 1.48$ & $16.72 \%$ & 6.8 & $0.000^{*}$ \\
\hline & Rt lateral flexion & $37.73 \pm 4.19$ & $43.73 \pm 1.57$ & $15.9 \%$ & 4.58 & $0.000^{*}$ \\
\hline & Lt lateral flexion & $35.46 \pm 7.8$ & $42.86 \pm 5.23$ & $20.68 \%$ & 5.44 & $0.000^{*}$ \\
\hline & Rt Rotation & $51.13 \pm 7.18$ & $57.93 \pm 4.11$ & $11.73 \%$ & 4.92 & $0.000^{*}$ \\
\hline & Lt Rotation & $49.26 \pm 9.7$ & $59.13 \pm 1.24$ & $20 \%$ & 3.91 & $0.002^{*}$ \\
\hline
\end{tabular}

they applied sustained natural apophyseal glides techniques with isometric exercise on patients having nonspecific neck pain, there was significant decrease in pain and significant improvement in functional ability when compared to those who were treated with sustained natural apophyseal glides techniques alone.

Our results were supported by Shahzada Iftikhar Hussain et al. [32], who concluded that Mulligan natural apophyseal glide mobilization technique NAGs for treatment of nonspecific neck pain has been confirmed to be more helpful than Grade I \& II Maitland mobilization in reducing pain, and restoration of function by progressing NPRS and NDI scores in patients having nonspecific neck pain.

Another agreement with Eui-Ju Shin 1 and Byoung-Hee Lee [33], who concluded that application of the SNAGs technique to middle-aged women with CGH is considered effective in decreasing the duration time of headache, and neck pain, as well as in development of neck function.

Also, our finding is consistent with Miller et al. [34], who stated in their systematic review regarding manual therapy and exercises for neck pain that combined mobilization and exercise had greater effect in reducing pain and improving functional abilitythan exercise only.

The results of the current study come in agreement with Barton\&Halyes [35] who concluded that maximal neck flexor muscle strength was decreased by $50 \%$ in patients with unilateral neck pain and headache compared with normal subjects. Other study has also pointed that strength of neck flexor muscle was significantly reduced in patients with cervicogenic headache [36] So, strengthening exercises for neck flexor help in managing the headache. Similarly,Rbiul Islam et al. [13] found that a reduction in cervical muscle strength was associated with cervicogenic headache, and deep flexors training was effective for the treatment of cervicogenic headache because improvement in muscle strength (isometric exercises) was a main cause $f$ reducing pain and improvingfunctional ability.

Also,JariYlinen et al. [37] investigated the effect of neck exercises on cervicogenic headache and reported that both stretching and strengthening exercises reduce neck pain and disability.

Shannon M Petersen [3] attributed the increasing mobil- ity and decreasing pain intensity in patients of cervicogenic headache to the application of neck manual therapy for (strengthening, stretching and mobilization exercises).

Our conclusion come in consistence with the work of Jull et al. [17] who examined the effectiveness of manual therapy and low load exercise program for individuals with cervicogenic headache. They reported that both manual therapy and specific exercise were effective in reducing headache frequency and intensity.

Also, our results can be explained by the work ofGema Bodes-Pardo et al. [25] who suggested that sternocleidomastoid muscle may be particularly a common source of myofascial CGH. So, stretching of this muscle is a main cause of improvement and treatment of CGH.

This study was limited by small sample size and un availability of Arabic version of Headache Disability Index.

\section{Conclusion}

Mulligan NAGs technique could be effective on decreasing pain intensity level, improving functional abilityand cervical range of motion in patients with cervicogenic headache.

Further studies would be worth while because CGH affecting sixtysix percent of the world wide population, Subjects with chronic cervicogenic headache have considerable limitation of daily function, restriction of social participation, and emotional distress with profound impact on qualityof life. future studies can consider a large sample size, pain threshold, Assessing electrophysiological parameters.

\section{Competing interests}

The authors declare that they have no competing interests.

Authors' contributions

\begin{tabular}{|l|c|c|}
\hline Authors' contributions & GIM & WSS \\
\hline Research concept and design & -- & -- \\
\hline Collection and/or assembly of data & $\checkmark$ & $\checkmark$ \\
\hline Data analysis and interpretation & $\checkmark$ & $\checkmark$ \\
\hline Writing the article & $\checkmark$ & $\checkmark$ \\
\hline Critical revision of the article & -- & -- \\
\hline Final approval of article & $\checkmark$ & $\checkmark$ \\
\hline Statistical analysis & $\checkmark$ & -- \\
\hline
\end{tabular}


Mohamed et al, Physical Therapy and Rehabilitation 2018,

\section{Acknowledgements}

The authors express their sincere gratitude

to all participants in the study.

Publication history

Editor: Gordon John Alderink, Grand Valley State University, USA.

Received: 14-April-2018 Final Revised: 18-May-2018

Accepted: 22-Jun-2018 Published: 03-Jul-2018

\section{References}

1. Nicholson GG and Gaston J. Cervical headache. J Orthop Sports Phys Ther. 2001; 31:184-93. | Article | PubMed

2. Classification and diagnostic criteria for headache disorders, cranial neuralgias and facial pain. Headache Classification Committee of the International Headache Society. Cephalalgia. 1988; 8 Suppl 7:1-96. | PubMed

3. Petersen SM. Articular and muscular impairments in cervicogenic headache: a case report. J Orthop Sports Phys Ther. 2003; 33:21-30; discussion 30-2. | Article | PubMed

4. The International Classification of Headache Disorders: 2 nd edition. Cephalgia. 2004; 24:9-160.

5. Nilsson $\mathrm{N}$. The prevalence of cervicogenic headache in a random population sample of 20-59 year olds. Spine (Phila Pa 1976). 1995; 20:1884-8. | PubMed

6. Dreyfuss $P$, Michaelsen $M$ and Fletcher $D$. Atlanto-occipital and lateral atlanto-axial joint pain patterns. Spine (Phila Pa 1976). 1994; 19:112531. | PubMed

7. Smith KL and Horn C. Cervicogenic headache part 1: an anatomic and clinical overview. J Man Manip Ther. 1997; 5:158-170.

8. Hagen K, Einarsen C, Zwart JA, Svebak S and Bovim G. The co-occurrence of headache and musculoskeletal symptoms amongst $\mathbf{5 1} 050$ adults in Norway. Eur J Neurol. 2002; 9:527-33. | PubMed

9. Fernandez-de-Las-Penas $C$ and Courtney CA. Clinical reasoning for manual therapy management of tension type and cervicogenic headache. J Man Manip Ther. 2014; 22:44-50. | Article | PubMed Abstract | PubMed FullText

10. Diener I. The impact of cervicogenic headache on patients attending a private physiotherapy practice in Cape Town. S Afr J Physiother. 2001; 57:35-39.

11. van Suijlekom HA, Lame I, Stomp-van den Berg SG, Kessels AG and Weber WE. Quality of life of patients with cervicogenic headache: a comparison with control subjects and patients with migraine or tension-type headache. Headache. 2003; 43:1034-41. | Article | PubMed

12. Sjaastad O, Fredriksen TA and Pfaffenrath V. Cervicogenic headache: diagnostic criteria. The Cervicogenic Headache International Study Group. Headache. 1998; 38:442-5. | Article | PubMed

13. Rabiul Islam, Nishat Quddus, Mohammad Miraj and Shahnawaz Anwer. Efficacy of deep cervical flexor strength training versus conventional treatment in cervicogenic headache. Int J CurRes Rev. 2013; 5:84-90. | Article

14. Henry P, Dartigues J, Puymirat C, Peytour P and Lucas J. The association cervicalgia-headaches: an epidemiologic study. Cephalalgia. 1987; 7:189-190. | Article

15. Zito G, Jull $\mathrm{G}$ and Story I. Clinical tests of musculoskeletal dysfunction in the diagnosis of cervicogenic headache. Man Ther. 2006; 11:118-29. | Article I PubMed

16. Garcia JD, Arnold S, Tetley K, Voight K and Frank RA. Mobilization and Manipulation of the Cervical Spine in Patients with Cervicogenic Headache: Any Scientific Evidence? Front Neurol. 2016; 7:40. | Article | PubMed Abstract | PubMed FullText
17. Jull G, Trott P, Potter H, Zito G, Niere K, Shirley D, Emberson J, Marschner I and Richardson C. A randomized controlled trial of exercise and manipulative therapy for cervicogenic headache. Spine (Phila Pa 1976). 2002; 27:1835-43; discussion 1843. | Article | PubMed

18. Mulligan B. Manual Therapy: "NAGS", "SNAGS" “Mwms". (5th edition). PlaneView Services Ltd, New Zealand. 2005; 9-34.

19. Moulson $A$ and Watson T. A preliminary investigation into the relationship between cervical snags and sympathetic nervous system activity in the upper limbs of an asymptomatic population. Man Ther. 2006; 11:214-24. | Article | PubMed

20. Kumar D, Sandhu JS and Broota A. Efficacy of Mulligan Concept (NAGs) on Pain at available end range in Cervical Spine: A Randomised Controlled Trial. Indian Journal of Physiotherapy and Occupational Therapy. 2011; 5:154-158.

21. Hawker GA, Mian S, Kendzerska T and French M. Measures of adult pain: Visual Analog Scale for Pain (VAS Pain), Numeric Rating Scale for Pain (NRS Pain), McGill Pain Questionnaire (MPQ), Short-Form McGill Pain Questionnaire (SF-MPQ), Chronic Pain Grade Scale (CPGS), Short Form-36 Bodily Pain Scale (SF-36 BPS), and Measure of Intermittent and Constant Osteoarthritis Pain (ICOAP). Arthritis Care Res (Hoboken) 2011; 63 Suppl 11:S240-52. | Article | PubMed

22. Fejer R, Jordan A and Hartvigsen J. Categorising the severity of neck pain: establishment of cut-points for use in clinical and epidemiological research. Pain. 2005; 119:176-82. | Article | PubMed

23. Shaheen AA, Omar MT and Vernon H. Cross-cultural adaptation, reliability, and validity of the Arabic version of neck disability index in patients with neck pain. Spine (Phila Pa 1976). 2013; 38:E609-15. | Article | PubMed

24. Malmstrom EM, Karlberg M, Melander A and Magnusson M. Zebris versus Myrin: a comparative study between a three-dimensional ultrasound movement analysis and an inclinometer/compass method: intradevice reliability, concurrent validity, intertester comparison, intratester reliability, and intraindividual variability. Spine (Phila Pa 1976). 2003; 28:E433-40. | Article | PubMed

25. Bodes-Pardo G, Pecos-Martin D, Gallego-Izquierdo T, Salom-Moreno J, Fernandez-de-Las-Penas C and Ortega-Santiago R. Manual treatment for cervicogenic headache and active trigger point in the sternocleidomastoid muscle: a pilot randomized clinical trial. $J$ Manipulative Physiol Ther. 2013; 36:403-11. | Article | PubMed

26. Dharti Hingarajia. The effect of deep cranio-cervical flexor (DCCF) training on sitting posture chronic neck pain. Int J CurRes Rev. 2012; 4:10-18.

27. Fernandez-de-Las-Penas $C$ and Courtney CA. Clinical reasoning for manual therapy management of tension type and cervicogenic headache. J Man Manip Ther. 2014; 22:44-50. | Article | PubMed Abstract | PubMed FullText

28. Exelby L. Peripheral mobilisations with movement. Man Ther. 1996; 1:118-126. | Article | PubMed

29. Mulligan B. R. Mobilizations with Movement (MWMS). J Man ManipTher. 1993; 1:154-156.

30. Gautam R, Dhamija JK, Puri A, Trivedi P, Sathiyavani D and Nambi G et al. Comparison of Maitland And Mulli-gan Mobilization in Improving Neck Pain, ROM and Disability. Int J Physiother Res. 2014; 2:561-6. | Pdf

31. Ali A, Shakil-Ur-Rehman S and Sibtain F. The efficacy of Sustained Natural Apophyseal Glides with and without Isometric Exercise Training in Nonspecific Neck Pain. Pak J Med Sci. 2014; 30:872-4. | PubMed Abstract | PubMed FullText

32. Shahzada Iftikhar Hussain, Ashfaq Ahmad, Freaha Amjad, Tariq Shafi and Hassan Anjum Shahid. Effectiveness of Natural Apophyseal Glides Versus Grade I and II Maitland Mobilization in Non-Specific Neck Pain ANNALS. 2016; 22:23-29. | Article

33. Shin EJ and Lee BH. The effect of sustained natural apophyseal glides on headache, duration and cervical function in women with cervicogenic headache. J Exerc Rehabil. 2014; 10:131-5. | Article | PubMed Abstract | PubMed FullText 
Mohamed et al, Physical Therapy and Rehabilitation 2018,

http://www.hoajonline.com/journals/pdf/2055-2386-5-8.pdf

34. Miller J, Gross A, D'Sylva J, Burnie SJ, Goldsmith CH, Graham N, Haines T, Bronfort $\mathrm{G}$ and Hoving JL. Manual therapy and exercise for neck pain: a systematic review. Man Ther. 2010; 15:334-54. I Article I PubMed

35. Barton PM and Hayes KC. Neck flexor muscle strength, efficiency, and relaxation times in normal subjects and subjects with unilateral neck pain and headache. Arch Phys Med Rehabil. 1996; 77:680-7. | Article | PubMed

36. Watson DH and Trott PH. Cervical headache: an investigation of natural head posture and upper cervical flexor muscle performance. Cephalalgia. 1993; 13:272-84. I Article I PubMed

37. Ylinen J, Nikander R, Nykanen M, Kautiainen $\mathrm{H}$ and Hakkinen A. Effect of neck exercises on cervicogenic headache: a randomized controlled trial. J Rehabil Med. 2010; 42:344-9. | Article I PubMed

\section{Citation:}

Mohamed GI and Shendy WS. Effect of natural apophyseal glides on cervicogenic headache: $\mathbf{A}$ randomized controlled trial. Phys Ther Rehabil. 2018; 5:8. http://dx.doi.org/10.7243/2055-2386-5-8 